\title{
THE CHANGING ETHOS OF THE UNIVERSITY: LIVING WITH SUPERCOMPLEXITY
}

\section{Introduction}

If a market model characterised by excessive bureaucratisation and reductionist control measures predominate the ethos of the university, nobody wins. Such is the argument posed by Clare and Sivil (2014); and Ensor (2015) who convincingly argue that the current neoliberal market ethos with its concomitant excessive bureaucracy results in a total loss of personal autonomy throughout all the ranks and sectors within the university. Furthermore, Weinberg and Graham-Smith (2012) maintain that the university as a capitalist corporate has lost its soul and its autonomy. Many authors have lamented and written extensively about the current business ethos - the compounded bureaucratisation and top-down managerialism in universities worldwide - an ethos inherently foreign to academia (Letseka 2008; Beckmann \& Cooper 2013 Vally \& Motala 2014;Tight 2014).

There is clearly a need to question the prevalent market ethos of university education worldwide currently dominated by a discourse of a fixed market-like corporatism, where knowledge is largely commodified and the university is primarily seen as a profitable business accountable to its 'customers' and the state. The prevalent discourse, often underpinned by a corporate neoliberal market ethos, is characterised by an emphasis on quantification to determine profitable commodities based upon a premise of certainty, predictability and control. I argue that this ethos is in stark contrast to the demands posed by age of supercomplexity. I draw on the work of Barnett (2000a), who described the age of supercomplexity as being characterised by 
uncertainty, unpredictability, challengeability and continual emerging interpretability (Barnett 2000a: 167).

Although Barnett (2000a: 6) concedes to the concept of a university operating in a global world where market-related forces inevitably infiltrate the domains of the university, he makes it clear that the manner in which universities deal with teaching and research should not adhere to the commodification demands of markets, neither should an institution like a university be constituted by the same rules as corporates, because a university is fundamentally different by nature, and in his words a mosaic on the move- that needs to lead the conditions of dynamic uncertainty. He notes that universities are no longer perceived as closed systems or so-called ivory tower institutions: on the contrary they are open, dynamic complex systems which are primarily defined by their internal relations within the university and at the same time their constant interactions with the external environment in which they are functioning.

\section{Argument}

The research on which this lecture is based focused primarily on the dramatic changes in the underpinning ethos and modes of thinking which have taken place within universities worldwide, from humane collegial organisations to market oriented corporate organisations predominantly focused on profitmaking and bureaucratic enforcement of rules and procedures. According to evidence in the literature, this tendency is rooted in American and British discourse (Thatcherism) during the 1970's and currently dominates thinking in higher education globally (Torres 2011; Braun 1999).

In this paper I indicate that this dominant mindset is incongruent with the true nature and purpose of a university, and a stumbling block for the university to function 
within an age of supercomplexity. I argue that another important purpose of a university is to discover and produce new knowledge, educating citizens by empowering them to become active agents who can address societal problems and thus make a difference in their world (Higgins 2013; Clare \& Sivil 2014). Moreover, according to Barnett(2000a) universities by nature have to foster dynamic uncertainty in order to question the status quo and create new knowledge. In this article I argue that the latter mission of the university militates against the prevalent drive for certainty pertaining to quantifiable production of useful "knowledge" for the market

\section{OUTLINE OF LECTURE}

- Firstly I will explain what is meant by a neoliberal market ethos,

- Secondly I interrogate the reasons why South Africa as a developing nation bought so wholeheartedly into the neoliberal paradigm of market -oriented profitmaking for universities.

- Subsequently I outline a few manifestations of this market ethos in universities and briefly demonstrate how it has affected academia within university education worldwide, but more specifically at home.

- Thereafter I allude to the notion of 'the age of supercomplexity', a phrase coined by Barnett (2000a) as my theoretical lens to indicate how the current ethos is failing academia in its very core and how inappropriate the prevalent ethos is in attempting to respond to the demands of the era in which we find ourselves. My main argument is that this is not an appropriate paradigm for the specific era of supercomplexity, let alone for a developing nation like South Africa with its specific historical background.

- I finally make some recommendations pertaining to new modes of thinking and indicate how these can provide constructive ways of dealing more appropriately with the demands posed by supercomplexity. 


\section{$3 \quad$ Neoliberal market ethos infiltrated the university domain \\ 3.1 Neoliberalism}

Neoliberalism provides the grounding discourse for the current alliances between universities, the state and business. Within the neoliberalism discourse, education is valued most for its ability to turn objects or ideas into things for the market, including turning students into better twenty-first century workers (Weldon et al. 2011: 8). This begs the question, where does this discourse, albeit foreign to the traditional ethos and value system underpinning university education all come from? Neoliberalism is embedded within the overarching concept of globalisation. Although globalisation is a multifaceted concept, it can be regarded as the key social, political and economic force of the twenty-first century. Nobody can deny the ubiquitous effects of globalisation on the world we live in. In general terms, globalisation seeks to spur advances in communications and ICT. These advances allow capital- both ideas and money- to move rapidly through international mediums of exchange and make it possible for vastly distant social relations events to shape one another (Weldon et al. 2011:8)

However, Torres (2011: 177) maintains that 'neoliberal globalisation is the most powerful form of globalisation predicated on the dominance of the market over the state, particularly through deregulatory models of governance that deeply affected the university in the context of academic capitalism'. This means that the university system, in an attempt to advance international competitiveness, has narrowed down the true task of a university, namely to serve as a site of contestation of the national and global order. In addition, Braun (1999) makes it quite clear that the adoption of a major ideological reform project of the Thatcher government initiated the neoliberal philosophy, based upon the belief that the government is no longer responsible to fund basic services, such as health, transport and education. The latter systems should compete with other sectors in the 'market' -a deceptive metaphor - for the 
economy - Neoliberal ideology thus boils down to Thatcherism which, by privatising social services such as health, education and transport, wanted to infuse the notion of a human capital theory that educational investments are directly linked to economic returns. Social and economic progress can thus only be achieved if education systems fulfil the needs of the market. (Vally \& Motala 2014). In an age of globalisation, the ideology of neoliberal globalisation links education with the requirements of the global knowledge economy Hence, the goal of education is narrowed down to become human capital development, which threatens humanistic democratic rights and value systems behind publicly financed systems. (Giroux 2014) Holistic human development, via lifelong learning and creating socially just and democratic communities is thereby weakened and frowned upon, as if outdated. (Dahlstrőm \& Lemma 2008) Education is seen as a global commodity and as economic market forces infiltrated discourses in $\mathrm{HE}$, universities started to engage in the commercialisation of intellectual property and competition for students and academic staff. Productivity, marketable skills and market responsiveness increasingly became the dominant discourse;(Zehle 2012:116).

Market in this context is a metaphor for competition in a global knowledge economy (Weldon et al 2011). Marginson (2014) maintains that politicians often use the 'free market' metaphor as an excuse for the devolution of responsibility for outcomes from government to higher education institutions and thus to legitimise the limitation of government subsidy to universities. Hence the discourse of competing via branding in the open free market, becomes the default discourse for universities as if education is a product that can be sold, similar to any other product. Thus the university's main focus changed from serving the common good in the society at large to serving the so-called 'global knowledge economy'. Giroux (2014;56) quotes Ellen Schrecker who observes that "in England and the USA, universities and businesses are forming stronger ties, the humanities are being underfunded, student tuition is rising at astronomical rates, knowledge being commodified and research is valued, no longer 
by looking at the actual substance of new knowledge produced, but rather through the lens of a bureaucratic and quantifiable audit culture.

In the light of all of this the university has to be re-invented in order to function appropriately within an era of supercomplexity. Subsequently the question arises, What are the main purposes of a university? I argue that the overall purpose of a university pertains to its contribution to humanise society, as opposed to a reductionist focus on performativity, as if people are 'products for the market' with a view to profitmaking. In other words, my argument centres on the plea for universities to foreground values such as respect for the "truth" in a diverse society, for human dignity and for all living beings- even more so in a developing country such as South Africa. Arendt (1958) maintains that the subject of education is 'becoming a human being' while Higgins (2013) describes higher education as the development of 'critical literacy' which the humanities are so uniquely situated to develop. It is precisely this mode of thinking that is beneficial to society which is in dire need of humane values of compassion, human dignity and social justice something which clearly differs from the reductionist commodification and profitability of knowledge favoured by market fundamentalism (Vally \& Motala 2014). Simply put: market fundamentalism refers to an inappropriate and literal application of the dominant economic ideology of neoliberalism currently being enforced within higher education institutions, especially in the United Kingdom and the USA and recently adopted by some South African universities (Wolhuter, CC Higgs P, Higgs LG, Ntshoe ,2009). According to Vally and Motala (2014) market fundamentalism, which infiltrated the dominant thinking in some South African universities leads to the detriment of their educational calling for the common good which should benefit society at large. They go on to say that it is even more important to foreground humane values such as compassion, respect for human dignity and social justice in the South African context where we have to come to grips with past 
injustices, inequalities, so many societal problems, and particularly low levels of academic literacy.

\subsection{Reasons why South Africa imported neoliberal policies}

One could easily ask the question: How did all these foreign notions, predicated on a corporate business, such as 'outsourcing' 'cost-cutting measures' 'performance appraisals', and 'students as customers' infiltrate the South African higher education scene so successfully? Soudien and Corneilse (2000: 299-314) maintain that one of the main reasons for the prevalent and predominant market ethos, especially in a developing country such as South Africa, is the underlying tension and confusion between globalisation discourses and local or national priorities. I think this is especially the case in the post-apartheid era, when political decisions have been taken to 'catch up' with global trends and discourses after the long period of isolation. In a recent article, Soudien (2014) attributes this phenomenon in South African higher education to progressivism. Higgins (2013) cites a pertinent example of how the minister of Higher Education and Training, Dr Blade Nzimande, revised the Higher Education Act to become the Higher Education and Training Laws Amendment Act (2012) which allows him to intervene and issue directives to any university that does not comply on a range of matters. This move centres on the issue of a dramatic cut in government subsidy to universities, and measures to make universities toe the line when the National Funding Formula (NFF) subsidy formula has been altered (Higgins 2013: 38).

Vally and Motala (2014) illustrate this point in a South African context by using the term 'market fundamentalism' within the broad confines of neoliberal globalisation. They argue that the state - specifically in a developing country such as South Africa - has an obligation to educate citizens and not to 'outsource' its responsibility by encouraging privatisation of education institutions, thus denying poor people 
affordable access to education and leaving room for competitive businesses to make money out of a what they argue is a basic human right, enshrined in the Constitution. They claim that many South African citizens are being brain-washed through print and electronic media who 'sell' over-simplistic clichés such as 'education fails to provide young people with skills for employment', as if there is a simplistic and direct link between education and full employment or economic growth. They state that 'education is not simply the handmaiden for solving the problems behind low economic output [...] as there are a range of exogenous factors involved and reasons why education and training does not automatically lead to full employment (Vally \& Motala 2014). They conclude by emphasising that if the power of money ultimately determines the decisions of the state pertaining to the direction of education, including higher education, we as South Africans will not be able to develop and shape a humane and democratic society In their book, Education, Economy and Society, Vally and Motala (2014:1) successfully exposed the false assumption of human capital theory which underpins the market paradigm of neo-liberalism, that an education system is responsible for job creation. Alexander puts it succinctly in the forward:

Once the commodity value of people displaces their intrinsic human worth or dignity, we are well on the way to a state of barbarism...until we bring back into our paradigms and thus our social analyses, the entire human being and the ways in which human beings can live fulfilled lives beyond their mere economic needs, we will continue to promote anti-human philosophies and policies that ultimately tend to work to the benefit of those who have and to the detriment of those who do not"

This mode of thinking and its concomitant market ethos of honouring a supply and demand principle and money-making as the most important value is rapidly penetrating higher education at the expense of the core commitment of a university, namely to educate citizens for a humane, just and democratic society (Kistner 2007: 
14). Makhanya (2015: 31) echoes similar thoughts by pointing to the dangers of accepting simplified formulae as panaceas for solving all ills in higher education. He goes to say that neither advances in technology nor profitmaking per se will enable universities to deliver contextually relevant education to the nation. He maintains that at the University of South Africa:

"We believe that technology should be an instrument for achieving excellence in scholarship, student support, institutional efficiency and service delivery, but that should not dictate a business model based on potential, possibility and profit to the university”.

\section{$4 \quad$ Manifestations of corporate ethos in academia}

\subsection{A loss of collegiality}

The adoption of corporate practices by higher education institutions is rapidly transforming the educational landscape. Universities were once thought of as institutions for public good, serving the interests of the community in which they are embedded as well as the interests of the citizens of the world. Today education is largely viewed as a marketable commodity. Students have been transformed into consumers and programmes are being regarded as successful only when they drive revenue production and support the acquisition of corporate funding. The concern of any institution of learning with a corporate nature is to meet the demands of the consumers in the most efficient and cost-effective manner. Hence the broad goals of education in its relation to the society in which it is embedded have been undermined. In similar vein, Johnston (2011: 180) warns against the danger of the narrow definition of what it means to be educated to mere instrumental rationality which in turn erodes the critical reflection dimensions and the underlying capacity to include making morally responsible choices and becoming accountable citizens. In institutions of higher learning the packaging of knowledge as commodities as well as an over-emphasis on quantifiable 'outputs', directly linked to money, leads to a 
decreasing of humane values, such as caring and compassion. Students become 'consumers' of knowledge as 'products'. They believe that they have the right to demand goods because of the money that they paid. Such a state of affairs eventually leads to a devaluing of learning as a lifelong process and hence a loss of people's opportunity to become educated human beings capable of compassionate behaviour towards one another. For academics it means a loss of collegiality in favour of competitiveness and a predominant consumerist value system which does not do justice to humanising society at all (Natale \& Doran 2012: 189). Similarly, Weinberg and Graham-Smith (2012: 68-76) maintain that the university has lost its distinctiveness in the era of advanced capitalism and has become just another corporate. Consequently, the profit motive has left nothing untouched, let alone the structures and procedures inherent to the prevalent nature of corporate governance. In their article, they regret the loss of collegiality as they point to the merits of collegial governance which was nuanced and adaptable to the eccentricities of the academic mind. Furthermore, they argue that collegiality has emphasised the commonspiritedness of debating appropriate academic principles by allowing dissident voices until agreement is reached. Apart from governance, collegiality enriches academia as it inherently transcends boundaries between students and professors, junior lecturers and professors by sharing interests and nurturing the potential of all parties involved.

\subsection{Scaling down of non-profitable courses}

To improve efficiency, universities may close down courses that do not attract big numbers regardless of whether they have inherent educational value. Courses such as the humanities, languages and the arts are closed in the name of cost-cutting and costeffectiveness because the only criterion that matters is the economic value (Natale \& Doran 2012:188). Although this is not true for all South African universities, Bosman (2014) laments the diminishing status granted to the teaching of the humanities at the 
University of South Africa precisely because of the narrow-minded utilitarian views on knowledge which are arguably directly linked to student numbers and costeffectiveness. He points to the fact that there is a loss of status in the domain of the humanities, all those fields which cannot directly translate to money-making skills (Bosman 2014: 67-87). He argues that if a futile distinction is made between 'useful' and 'useless' knowledge, where knowledge of languages, music, arts, sociology are narrowly defined as useless knowledge, whereas knowledge linked to economics and business are linked to useful knowledge, and the university buys into such a mindset, money-making skills would be favoured at the cost of the humanities and humane values. He rather advocates a broad definition of knowledge where knowledge, skills and values alike are acknowledged. Instead of only asking what can be done with this knowledge and skills, one may then also ask what certain knowledge, values and skills embedded in the humanities can do for the individual as well as for the common good in society. The thinking behind the utility and hence money-making value of knowledge fields is underpinned by the supply and demand principle of the market. The latter mode of thinking directly led to the literal adoption of the cost unit principle within the University of South Africa This mode of thinking implies for example, that humanities, arts, languages and music which could seldom attract huge student numbers, similar to subjects like business management and economics are being scaled down or even closed down. My argument is that the principle of crosssubsidisation was much more in line with protecting valuable knowledge and humanising potential for the university.

In similar vein, Higgins (2013) makes a powerful case for the important role the teaching of the humanities should play, especially in South African universities. He contends that we 'need to get real' in terms of our own context and history, where citizens need a language of 'critical literacy' to be able to discern, wisely and justly, in an unequal society where many social problems need to be addressed and attitudes of respect for human life, for diversity and nature can be cultivated. Higgins (2013: 120) further argues that critical literacy 'calls the bluff of authority/power abuse, 
questions sources, closely examines offered authenticities, read contextually and comparatively, [and] identifies conventions to determine meanings'. Higgins makes a strong argument for the necessity of the humanities as a field of study at any university by saying that higher-order reading and writing underpin the majority of humanities education at university level and that those advanced skills are a prerequisite to successfully entering into any science and technology studies. Ensor (2015: 21) concurs with the sentiments of Higgins by pointing to the importance of the offering of the humanities, performing arts, languages, philosophy and religious studies recognised and prioritised by the University of Cape Town.

\subsection{Neglect of teaching tasks in favour of quantifiable research outputs}

Following on the general importance of reading and writing skills, quality university teaching is equally important and yet currently devalued in favour of research outputs. Throughout the world, authors such as Molesworth et al;2009) make the point that many universities over-emphasise and over-prioritise research outputs at the cost of teaching tasks because research outputs generate a great deal of revenue for the university. The recent revision of the national funding formula (the NFF) in South Africa is a case in point (DHET 2012). Some universities may also reduce the hours of teaching, or may appoint less teaching staff, which results in a higher teacher/student ratio .All these measures gradually create a cost-effective mode of thinking, more conducive to situations of economies of scale which often favour reproductive learning instead of critical thinking and reflection and quality education (Molesworth et al. 2009). Ramsden (2003) points out that the increased reliance on performance management systems, typically used in a corporate environment did not lead to quality in teaching and learning in Australian and UK universities; on the contrary, any external pressures formed an inadequate basis for enhancing quality in academia. 
In an interview conducted with Craig Calhourn, director of the London School of Economics and Political Science, Vale (2014: 38-39) reflected on the changing nature of the university as follows:

"Universities must put teaching at the front and centre, because it is still necessary to retain old values of higher education, such as the promotion of a public discourse that matters to democracy, creating opportunities for human development in the broadest sense, including the intellectual, social, moral dimensions of education, something which the humanities are ideally positioned to make.”

This view is highly relevant in South Africa, where the majority of the people missed out on quality higher education in the past. To exacerbate the loss of a broad based education where social and moral debates could flourish, there is ample evidence in the CAP survey (Wolhuter,et al 2009) that many South African academics find themselves within a highly prescriptive environment as the climate of many South African universities have changed dramatically pertaining to the creation of excessive rules and procedures which stifle creativity and spontaneity.

\subsection{Excessive bureaucracy and loss of autonomy}

Clare and Sivil (2014: 60-71), who dealt with the rise of excessive bureaucracy in universities, convincingly indicated that both academics and administrators in such institutions lost their autonomy as a result. This happened because once a bureaucratic system is firmly established it takes on a life of its own - although not necessarily intended. They point out how irony underpins the logic of bureaucracies. The hierarchy of rules requires interpretation which is always subjective. To eliminate the subjectivity, more rules are made which are again open to subjective interpretation. Consequently, the ever-increasing number of rules and more 
administrators needed to oversee others to implement the rules result in 'administrative bloat'. Eventually, all the existing roles of teachers, researchers, administrators, and leaders change dramatically (Clare \& Sivil 2014: 66). What was called administration and even leadership are replaced by the notion of 'management'. Teachers become impersonal purveyors of knowledge and from a bureaucratic point of view could be replaced by a teaching machine. Over time a general loss of trust and a culture of suspicion develop and give rise to feelings of being dominated by the system. The subsequent dehumanising effect reduces every worker, including management, into 'cogs of the bureaucratic machine' (Clare \& Sivil 2014: 67.This view echoes Weinberg and Graham-Smith’s (2012: 77) contention that the corporatisation of the university causes a loss of identity and autonomy which in turn erodes the academic sense of vocation and ultimately yields to self-interest or to serve the market.

\subsection{The rise of managerialism, and rigid hierarchical structures}

The excessive system of bureaucratisation has led to increased rigid hierarchies and divisions between different sectors within the university. A good example of such division is the one between academics and management which gave rise to managerialism - a culture of 'us' and 'them'.

Moreover, according to the market paradigm, the recruitment of university leaders is often based on business acumen and less on expertise in education and the leaders' commitment to learning. Executive managers are often appointed with the assumption that they do not need knowledge about the field or the institution per se, as if managing people and their knowledge is a mechanical process. This often leads to all sorts of problems ranging from the person's lack of experience of the specific context (including the history of an organisation), inadequate understanding of where 
people are in terms of their needs and aspirations, and the specific conventions, regulations and organisational culture of the institution. These factors often result in a period of paralysis or 're-inventing the wheel' until staff has gained trust in the new manager and he or she has eventually caught up in experience. Furthermore, Winter (2009) points out that conflicting values and different needs of academics and managers are sometimes a bone of contention and potential sources of mistrust if not made transparent by the university. However, authors such as Burnes, Wend and Todnem (2014) have suggested that it is possible to blend collegiality and managerialism together if management can be structured to elect leaders.

While the role of management was previously to support the academic core of the university, a system of managerialism developed, according to which rigid rules could be enforced upon academics who no longer had any autonomy or veto power. The university favours quantifiable research outputs as a major source of revenue at the cost of teaching tasks. The arts and humanities are generally scaled down according to their lack of cost-effectiveness and inherent lack of quantifiable usefulness. I have explained the possible reasons for the above-mentioned manifestations of the neoliberal market ethos which has infiltrated the university system worldwide.

However, I have argued that this state of affairs is not suitable for South African universities in particular, because of its dehumanising effects on our society and developing democracy. I have also pointed to the fact that such a profitmaking and market ethos is not appropriate for the age of supercomplexity in which we currently find ourselves, mainly because of the opposing value systems of markets and the supercomplex world. In the ensuing section I elaborate more specifically on the age of supercomplexity, by adopting views coined by Barnett (2000a; 2000b; 2015) as a lens to suggest more appropriate modes of thinking for the university.

\section{The age of supercomplexity}


To address the prevalent market -corporate ethos and to be able to make some suggestions towards adopting workable strategies to deal with this prevalent situation, I made use of Barnett's concept of supercomplexity in relation to the main functions of a university within the era of globalisation. He explains that 'we now live in a world subject to infinite interpretability' as a result of overwhelming sources of data within a multiplicity of competing frameworks. There is no secure hold on the world, nor is any absolute possible any longer. The values of the university as an institution are on a cusp, at a crossroads. We can only accept the multiple realities and reason together in favour of values which we have co-defined as an institution (Barnett 2000a: 75, 111-123).

Supercomplexity denotes a fragile world, where nothing can be taken for granted and where no frame of understanding or action can be entertained with certainty. The reasons for supercomplexity is not merely because of fundamental changes of the social and technological world, but the very ways in which we understand ourselves and feel secure about acting in the world. Hence we are faced with a triple set of challenges: namely, of understanding, of self-identity and of action( Barnett 2015:180 -183).

Furthermore, Barnett (2000b;260) points to the fact that the world of work requires flexibility, adaptability and self-reliance. Individuals have to take responsibility for continually reconstituting themselves in their lifespan and to give new definition in a current learning society.

Ironically, Barnett goes on to say, the university has in part brought about supercomplexity as the university as institution promotes dynamic uncertainty in order to be conducive to the production of new knowledge. Paradoxically, Barnett argues that while the university is partly responsible for the existence of supercomplexity, it simultaneously has to set some boundaries for it, or to 'tame' it in order to combat 'the will to power' and to prevent power struggles between different 
stakeholders within the university, such the unions and other administrative sectors (Barnett 2000a: 82).

Furthermore, in terms of the research function of the university, Barnett maintains that the university needs to create conditions where uncertainty is actively promoted as the university ought to be a site of organised inquiry for generating uncertainty in order to stimulate new knowledge. Hence, the scholarship task of the university is to generate supercomplexity and the educational task is to help students and staff to live with supercomplexity, and thus not to allude to any grand narratives. Thus research and teaching are established as an interdependent holy alliance, where academics ought to keep the fragility of knowledge creation alive, producing new inventions and bold formulations of ideas, while keeping the values for the common good in sight without succumbing to performativity per se. Academics as researchers need to practise the art of communication by negotiating their knowledge with conflicting interest groups. Furthermore, in a supercomplex world researchers need to provide the outside world with value-added frameworks and to become the conscience of society (Barnett 2000a: 151). In order for the university to perform its teaching function adequately in this age, and to enable students to become self-reflexive beings, students need to be made aware of the results of the latest research in their field of study. Letseka (2008) emphasises that lecturers should be abreast of the latest developments in ICT and expose students to these tools in order to prepare them adequately for the new world of work.

The question remains, how could one determine the ethos according to which a university could be managed? According to Barnett (2000a: 111), the conditions of supercomplexity refuse to be managed, as the university is in essence a 'mosaic on the move', which implies that different value systems will always be disputed and in need of continual debates amongst communities, fraught with political battles amongst different interest groups and stakeholders. In that sense it may present 
intractable problems to would-be managers, who wish to manage in a mechanical, neutral fashion or want to avoid constructing an ethos for the university. Barnett (2000a:111) states that 'managerialism digs its own grave as it produces an ethos in itself'. Instead, he maintains that in order to make sense of an ethos for the university, according to which it could be managed a mindset should be adopted whereby matters are accepted as they are. Barnett (2000a: 123) comments as follows:

\begin{abstract}
"We have to acknowledge that we are faced with multiple uncertainties and that nothing has any solid basis to it. We need to reason together and keep to our values, but will not necessarily reach a position of absolute clarity, security or purity. We all have to become self-ironists now.”
\end{abstract}

In summary, the above-mentioned quote emphasises the conflicting mindset and ethos between market -oriented thinking and complexity thinking. A market ethos demands certainty, quantification and compliance with predetermined goals, whereas an ethos of supercomplexity requires continual contestation and re-negotiation based upon dynamic uncertainty

Barnett (2000a: 134-138) maintains that three conditions need to be satisfied in constructing the university congruent to the age of supercomplexity. They are conditions of knowledge, interaction and communication. As far as the knowledge condition is concerned, it is important for the university to have a collective understanding of itself and its available resources. That means that all staff must have an understanding of the multiplying challenges and conditions of the university and its specific context. Next, he points to the fact that the more interaction takes place between different units within the university the more equipped it will be to function in an age of supercomplexity. Communication involves a mutuality of understanding between different units of the university and should lead to co-understanding, both at levels of conduct and epistemological levels of inquiry. 
In the last part of the article, I suggest more suitable coping strategies to live within an era of supercomplexity, which is imperative to keep the academic core alive and allow the university to fulfil its humanising role in society.

\section{Recommendations: Living with supercomplexity}

Based on an analysis of the characteristics of the concept of supercomplexity, how can new modes of thinking make a difference to our understanding of university education, currently dominated by an ethos of a fixed corporate entity to become a more flexible, living organism congruent to the age of super-complexity?

By changing modes of thinking I believe academics in the South African context will be able to challenge prescriptive rule-based discourses emanating from corporate market-orientated environments, because I believe such environments to be incongruent to the inherent nature of a university as a living value-driven organisation, as opposed to a profit-making business, in an age of super-complexity. I argue that corporatist thinking predominantly informed by market forces, the selling of goods to customers and profit making are foreign to the nature of academia, especially in an age of supercomplexity. In stark contrast to a market-driven ethos, and a rigid hierarchical top-down working environment, the notion of supercomplexity implies a flexible environment of contestation which needs to produce dynamic uncertainty and thus fosters the creation of new knowledge. This means that the university has to afford scholars conditions for contestation and creativity, where they are able to produce new knowledge and thus contribute to society and serve humanity.

Furthermore, supercomplexity asks for the university to focus on the needs of the specific society in which it is embedded, rather than trying to implement global concepts that do not necessarily fit the context of the local society. It is precisely the 
point that Barnett (2000a) makes, namely that universities are not closed systems as in ivory tower institutions, but are open, dynamic, complex systems which are primarily defined by their internal relations within the institution and at the same time their constant interactions with the environment in which they are functioning.

Moreover, supercomplexity suggests the notion of constant dynamic interactions within the university and within its broader environment. In this regard, the concept of a hologram is useful to illustrate the interconnectedness between parts and whole. In a hologram light is recorded and encoded so that a scene can be reconstituted in its full three-dimensionality. The entire scene (whole) is captured at each individual point in the hologram; hence each small piece of holographic plate contains enough information to represent the whole picture. That points to the part/whole relationship within a hologram. (Hurst 2010:241). In a university context, this would mean that the interrelationships and communication between the parts and the whole are key to the optimal functioning of the institution in an age of supercomplexity. In other words, if role players were to realise that the current inappropriate corporate and concomitant top-down hierarchical culture do not do justice to the functioning of a university as a living, dynamic, humane body, they could debate and articulate different value preferences and educational needs. In such a debate the dynamic interactions between the parts and the whole could be taken into account through what Barnett calls 'infinite interpretability'. The outcomes of such debates could lead to the emergence of better options and co-evolution of the institution (Barnett 2000a: 6).This reminds of the urgent call for communication and leadership skills, which in a globalised world are simultaneously more problematic and more urgent (Barnett 2000b:258).

In echoing supercomplexity, Hurst (2010: 246) advocates a thinking mode of 'constant critical awareness' or a disposition of continual 're-negotiating options' and choices as our knowledge of the exact situation (reality) is limited and flawed. We have to fundamentally accept the notion of paradoxes and double binds as indices of 
deeper reality when living in a complex world; hence she advocates continual mapping of problems. Continual mapping suggests a reflexive mode of thinking which allows for flexibility and adaptability as opposed to adhering to rigid predetermined goals and plans, sometimes despite the proven futility of those plans and regulations in an ever changing dynamic circumstances. This becomes possible if we are accepting things as they are, prepared to give up certainty and predictability, and embrace dynamic uncertainty congruent to the era of supercomplexity. Barnett (2015:33) maintains that the university has both to produce (research function) and help us live with dynamic uncertainty (teaching). Hence in an age of supercomplexity interrelationships and continual contestation are key characteristics, as opposed to compliance to rigid bureaucratic rules.

He goes on to say:

The incoherence and paradoxes that are apparent in the postmodern university cannot be solved. They have to be lived with. The university will survive, it will gain social credibility, by showing its capacities to assist in the expansion of the pools of uncertainty, unpredictability, challengeability and contestability that structure the postmodern world. The university has to find ways of doing justice to all grand narratives that are invested in it. Technical reason, performativity, public projection and managerialism have to live with emancipation, citizenship, democracy and self-identity. To all these agendas, others will be added, some by the university itself. This is not an easy task, but easiness is not available to us"

Cilliers (2006: 105-112) addresses the issue of how to cope better with the demands of a supercomplex world wisely. He makes an argument against inappropriate fastness and unreflective speed. He is particularly concerned about the concept of speed in alignment with notions such as efficiency, success, quality and importance. He argues that a slower process is necessary, not only for the survival of certain important humane values not because of romantic ideals, but because it allows us to 
cope with the demands of a complex world in a better way. Cilliers (2006: 109) thus advocates the adoption of what he calls 'a certain slowness', as a mode of thinking to cope better with the demands of a complex world. He maintains that a slower approach - where appropriate - will enable us to retain our creative energy in the face of information overload, and sometimes irrelevant noise. He illustrates his argument by referring to the incidence of many popular movements which could be seen as characterising a culture of slowing down. One example is slow food as opposed to junk food, where making food with good nutrients and enjoyment as primary aims contest the idea that food necessarily has to be prepared quickly. On the contrary, good food is associated with slower processes in the preparation and creates a sense of awaiting the final product with greater expectation to enhance fulfilment. Another example is that of the slow schooling movement that questions educational achievements in a world geared for instant results. This movement emphasises contextual knowledge and reminds us that education is a process and not a product or commodity, which means that the journey is more important than the destination.

The conclusion of all these examples is obvious. Humane endeavours of sophisticated quality are characterised by the fact that they take time. This mode of thinking works against the notion of commodification of education, with a view to cost-effectiveness or cost-cutting at universities. Certain practices come to mind when adopting this thinking mode: in academia the notions of 'publish or perish' and 'fast tracking' to speed up promotions, need to be revisited. The over-emphasis on quantification of outputs, due to a predominant money-making ethos, often leads to a decline in quality and substance - all of which can make a mockery of higher education. Moreover, the importance of a certain slowness when changes need to be effected cannot be overestimated. More time for reflection will not only ensure proper and appropriate implementation of novel strategies but will allow for superior quality and more feedback time if unexpected things emerge. 
Arendt H (1958) The Human Condition. Chicago: University of Chicago Press.

Barnett R (2000a) Realising the university in an age of supercomplexity. London: Open University Press.

Barnett, R (2000b)Supercomplexity and the curriculum. Studies in Higher Education, 25(3):255-265

Barnett, R (2015) Thinking and rethinking the university. London and New York: Routledge

Beckmann A \& Cooper C (2013) Neoliberal globalization, managerialism in higher education in England:

Challenging the imposed order of things. Educational Policy Analysis and Strategic Research, 8:5-24

Bosman PR (2014) The school of Athens: moments in the history of an idea. Akroterion 59:67-87.

University of Stellenbosch.

Braun D (1999) Changing governance models in higher education: the case of new managerialism. Swiss Political Science Review 5(3):1-24

Burnes B, Wend P \& Todnem, R (2014) The changing face of English universities: Re-inventing collegiality for the twenty-first century. Studies in Higher Education 39:905-926

Cilliers P (2006) Complexity and Philosophy: On the importance of a certain slowness. ECO, 8(3):105-112

Clare J \& Sivil R (2014) Autonomy lost: bureaucratisation of South African HE. South African Journal of Higher Education 28(1):60-71

Dahlstrőm L \& Lemma, B 2008. Critical perspectives on teacher education in neo-liberal times: Experiencesfrom Ethiopia and Namibia. Southern African Review of Education, Vol 14, (1-2):29-42

Department of Higher Education and Training. (2012) Revised Higher Education and Training Laws Amendment Act.

Giroux, HA. 2014. Neoliberalism's war on higher education. Chicago Illionois: Haymarket books.

Ensor P (2015) UCT values the humanities above profits. Mail and Guardian, Feb20-26: 21

Higgins J (2013) Academic freedom in a democratic South Africa: Essays and interviews on higher education and the humanities. Johannesburg: Wits University Press

Hurst A (2010) Complexity and the idea of human development. South African Journal of Philosophy, 29(3):233-252

Johnston J (2011) Interrogating the goals of work-integrated learning: Neoliberal agendas and critical pedagogy. Asia-Pacific Journal of Cooperative Education, 12(3): 176-182

Kistner U (2007) Excess beyond excellence: the university beyond the balance sheet. South African Journal of Higher Education 5(1):25-40

Letseka M (2008) The challenges of university teaching and learning in the era of managerialism. Africa Education Review 5(2):305-323

Makhanya M (2015) Let us look soberly at the future. Mail and Guardian Aug 7-13: 31

Molesworth M, Nixon E \& Scullion R (2009) Having, being and higher education: the marketization of the university and the transformation of the student into consumer. Teaching in Higher Education (3):277-287

Morin E (2008) On complexity. New Jersey: Hampton Press Inc. 
Natale SM \& Doran C (2012) Marketization of education: An ethical dilemma. Journal of Business Ethics 105:187-196. Springer

Ramsden P (2003) Learning to teach in higher education. ( $2^{\text {nd }}$ edition). London: Routledge Falmer.

Soudien C (2014) Inclusion, innovation and excellence: Higher education in South Africa and its role in social development. South African Journal of Higher Education 28(3):907-922

Soudien C \& Corneilse C (2000) South African higher education in transition: global discourses and national priorities. In Stromquist NP \& K Monkman (eds). Globalisation and Education: Integration and contestation across cultures. New York: Littlefield publishers.

Tight M (2014) Collegiality and managerialism: A false dichotomy? Evidence from the higher education literature. Tertiary Education and Management. http://www.tandfonline.com/loi/rtem20

Torres CA (2011) Public universities and the neoliberal common sense: seven iconoclastic theses. International Studies in Sociology of Education 21(3):177-97)

Vale P (2014) Fight back! Universities must put teaching at their front and centre. Mail and Guardian, 3-9 Oct: 38-39

Vally S \& Motala E (2014) Education, Economy and Society. Pretoria: Unisa Press

Weinberg AM \& Graham-Smith G (2012) Collegiality: Can it survive the corporate university? Social Dynamics 38(1):68-86.

Weldon PA, Rexhepi J, Chang CW, Jones L, Layton LA, Liu A, McKibben S, Misiaszek G, Olmos L, Quon A and Torres CA (2011) Globalization and higher education in Southern California: views from the professoriate. Compare 41(1): 5-24

Winter R (2009) Academic manager or managed academic? Academic identity schisms in higher education. Journal of higher education policy and management 31(2):120-131

Wolhuter, CC, Higgs, P, Higgs, LG and Ntshoe, IM. 2009. Africa Education Review, 6(2):269-282

Zehle, Jana. 2012:116). Towards higher education in a post-neoliberal future: A comment on Ethiopia, Southern African Review of Education, 18(1): 114-123 